\title{
Managing educational process in university based on database management system
}

\author{
Mironova Ljudmila Ivanovna \\ Construction institute of Ural Federal University named \\ after the first President of Russia B.N. Yeltzin, \\ UrFU, \\ Yekaterinburg, Russian Federation City, \\ mirmila@mail.ru
}

\author{
Kadyrov Alexander Sabirjanovich \\ Construction institute of Ural Federal University named \\ after the first President of Russia B.N. Yeltzin, \\ UrFU, \\ Yekaterinburg, Russian Federation City, \\ alexander-kad@yandex.ru
}

\begin{abstract}
In the article, the process of informatization of education from the point of view of automation of document flow in higher education institutions is considered. Management of the office-work process, proceeding in higher education institutions, deals with the sphere of educational management. A technical basis of educational management in the higher education institution is the unified information system (UIS) allowing operating all processes proceeding in it. One of the UIS functions is administrative and information management within which UIS integrates means of IT support and automation of management of the educational institution. The purpose of the article is consideration of technology of system development automation of office-work on the basis of the database management systems (DBMS). The analysis of DBMS Microsoft Access DBMS and MySQL DBMS has allowed one to allocate their merits and demerits and to give preference of the last as it is capable to ensure functioning in the multiuser mode, thanks to existence of the client-server mode that is one of decisive factors of automation of the process of document flow in higher education institution. The design of the database, the special software of MySQL Workbench, which application has allowed one to accelerate working processes, was used, and the issue of reliability of data storage has been resolved thanks to their storage on the server possessing high technical characteristics and working at uninterrupted food. The organization of the specialized interface is shown as the example of SQL-of inquiries to the database. Within the real research, the technology of development of the database for automation of document flow of three structural divisions of the Ural institute of economy, there is management and the right with use of MySQL DBMS. It describes: selection committee, human resources department, dean's offices. As an example in the article, the technology of development of the interface of the database with use of MySQL DBMS for one division of the higher education institution is described. The approach offered in article can be used for improvement of educational management on the basis of means of information and communication technologies in other educational institutions. The article can be of interest to experts of the sphere of the information technologies, engaging in development of means of informatization in the context of development of the information and education environment of educational institution.
\end{abstract}

Keywords-CRM-System; flow of documents; customer; performer; clients; organizational management process; personal data; teacher; process approach; scheduling; student; DBMS; management.

\section{INTRODUCTION}

In research article, the process of informatization of education from the point of view of automation of document flow in higher education institution is considered. Office-work process control, proceeding in the higher education institution, belongs to the sphere of educational management. A technical basis of educational management in the higher education institution is the unified information system (UIS) allow controlling all processes proceeding in it. One of the UIS functions is administrative and information control, within which UIS integrates means of IT support and control automation by the educational institution. The purpose of the article is reviewing the technology of system development automation of office-work on the basis of the database management systems (DMS). The analysis of two database management systems of Microsoft Access DBMS and MySQL DBMS allow selecting their merits and demerits. In addition, it gives preference to the latter, as it is capable to ensure functioning in the multi-user mode, thanks to existence of the client server mode that is one of decisive factors in case of automation of the process of document flow in the higher education institution. In case of design of the database the special software of MySQL Workbench which application allow accelerating worker processes was used, and the issue of reliability of data storage was resolved thanks to their storage on the server, possessing high technical characteristics and working in case of uninterrupted power. The organization of the specialized interface is shown as the example of SQL-of database requests.

Within the real research, the technology of development of the database for automation of document flow of three structural subdividings of the Ural institute of economy, management and the low use of MySQL DBMS are considered. It describes selection committee, human resources department, dean's offices. As an example, in article the technology of development of the interface of the database with use of MySQL DBMS for one subdividing the higher education institution is described. The approach offered in the article can be used for enhancement of educational management on the basis of means of information and communication technologies in other educational institutions. The article can be of interest to experts of the sphere of the information technologies which are engaged in development 
of means of informatization in the context of development of the information and education environment of educational institution.

\section{RELEVANCE OF THE RESEARCH}

One of the priority directions of process of informatization of modern society is education informatization - introduction of means of new information technologies in an education system. It gives the chance to improve mechanisms of the management of an education system on the basis of use of the automated databanks scientifically - pedagogical information, information and methodical materials, organizational and administrative resources, and also communication networks.

Management of educational institution on the basis of the information technologies (IT) is the key mechanism which will allow one to create advantages in the competitive environment. In this regard creation of reliable and effective infrastructure, introduction of the unified ways of access to corporate data, improvement of controllability of all complex of information resources, and also ensuring compliance of infrastructure to strategic objectives of higher education institution [4] become the main actions in development of informatization.

In this article, the analysis of two database management systems (DMS) of the Microsoft Access and MySQL for the purpose of use of one of them for development of the database for document management in higher education institution is carried out (on the example of subdividings of the Ural Institution of Economics, Management and Low (Yekaterinburg).

\section{TheORETICAL BASES OF DESIGN OF DATABASES}

According to the typification of electronic editions of educational appointment which is carried out by Robert I. V., [14], one of their functions is automation of office-work in educational institution. Management of the office-work process proceeding in higher education institution treats the sphere of educational management $[11,12,15]$. Educational management of higher education institution is understood as purposeful organization of events, the processes promoting ensuring quality of educational activity by the rational organization, including management of education and effective use of personnel potential, development of technical and technological base $[8,9$, $10,13,16,17]$.

Technical basis of educational management in higher education institution is the unified information system (UIS) allowing to operate all processes proceeding in higher education institution (administrative management and management accounting, finance, management of educational process, management of information resources, actually educational process, scientific research, etc.). UIS of higher education institution is the reliable and effective infrastructure providing introduction of the unified ways of access to corporate data, the improving controllability of all complex of information resources of higher education institution [11].

For high-quality and productive functioning of UIS it is important to define structure of categories of users which depends on the UIS functions. Traditionally carry to the UIS functions: function of electronic training (UIS is intended generally for realization of processes of electronic training), function of administrative and information management (UIS integrates means of IT support and automation of management of educational institution), directory function (UIS acts as the open information system focused on users whose interests are connected with education).

As a research objective is development on the basis of the DBMS of system automation of office-work in some subdividings of the Ural Institution of Economics, Management and Low (UIEM\&L), which choice is restricted to article volume, the analysis of materials according to databases was carried out.

The database - a set of the data which are stored some ordered method. In other words, the database is a data store. Without the database management system (DMS) databases in itself aren't of interest. The DBMS is a set language and software which provides data access allows one to create them, to change and delete, ensures data security. In other words, the DBMS is the system allowing to create databases and to manipulate the information which is stored in them. The data access of the DBMS is provided by means of the special SQL language.

SQL - a structured query language which main objective is provision of an easy way of reading and data recording in the database [1]. For creation of system of automation of document flow two large Microsoft Access and MySQL DBMS on purpose detections of their advantages and shortcomings were analyzed.

DBMS Microsoft Access

Microsoft Access - a database management system which is included by Microsoft in composition of the professional editorial office Microsoft Office. Access DBMS occupies one of the leading places among systems for design, creation and processing of databases. Access DBMS is simple in a study and operation, is as a result available to wide number of users, is supplied with extensive means on creation of the reports of different level of complexity created on the basis of tables of different formats. As a rule, Access is used for creation of the personal databases which do not have commercial distribution.

This DBMS is relational, represents a set of interdependent two-dimensional tables (relations). It is used for creation and processing of local databases or as client applications with access to remote and to distributed databases of collective use with the SQL Server or Oracle. The DBMS has uniform technology of creation and use of databases, forms, requests and reports. In it there is a possibility of collaboration with other external data sources (databases from Access DBMS and other DBMS types, electronic spreadsheets of Excel, text files). At the same time development tools of applications of the user can be used for operation with other DBMS (for example, MS SQL Server, Oracle), executing a role of an integrated development environment, using for data storage of a basis with different DBMS. Possible data types which are supported by Microsoft Access [2] DBMS are given in Table I.

In Access DBMS is available many different masters, designers and composers. Complete russification of Access DBMS (including names of fields and properties), simplicity in operation. In the given DBMS, there is no chance of application creation in the form of an executable file and simultaneous direct operation with several bases from a basis window. There is no own programming language (the Visual 
Basic programming language is used). The database and all its objects (tables, requests, forms, reports, macros and modules) are stored in one file.

TABLE I. DATA TYPES OF MiCROSOFT ACCESSS DBMS

\begin{tabular}{|l|l|}
\hline \multicolumn{1}{|c|}{ Type } & \multicolumn{1}{c|}{ Description } \\
\hline Text & $\begin{array}{l}\text { It is applied to storage of lines at which length doesn't } \\
\text { exceed 255 symbols (for example, the employee's full } \\
\text { name, the name of goods, the address, etc.) }\end{array}$ \\
\hline $\begin{array}{l}\text { Field } \\
\text { MEMO }\end{array}$ & $\begin{array}{l}\text { It is used for storage of the multilower case formatted text } \\
\text { (all parameters of a font also remain). It is applied to } \\
\text { storage, for example, characteristics of the employee, the } \\
\text { description of structure of a product }\end{array}$ \\
\hline $\begin{array}{l}\text { Numeric } \\
\text { al }\end{array}$ & $\begin{array}{l}\text { It is used for storage of various types of numbers, both } \\
\text { integer, and real }\end{array}$ \\
\hline Monetar & $\begin{array}{l}\text { It is applied to storage of monetary values. In the theory it } \\
\text { is the same numerical type, there is only no possibility of a } \\
\text { task of dimension of the field. }\end{array}$ \\
\hline Counter & $\begin{array}{l}\text { It is used for the description of a field which is set as } \\
\text { primary key. In the field of this type for each new record, } \\
\text { the unique number of the Long integer format is generated. }\end{array}$ \\
\hline $\begin{array}{l}\text { Date/tim } \\
\text { e }\end{array}$ & $\begin{array}{l}\text { It is applied to storage of values of calendar dates and time. } \\
\text { With the help "A field format», it is possible to set a type of } \\
\text { display of dates and time. "The short format of date" is by } \\
\text { default used. }\end{array}$ \\
\hline $\begin{array}{l}\text { It is used for storage of only two logical Truth/false values } \\
\text { Logical } \\
\text { ent }\end{array}$ & $\begin{array}{l}\text { This data type appeared starting with the Access 2007 } \\
\text { version. The field with the Attachment type allows adding } \\
\text { files (documents, figures and others). The size of one added } \\
\text { file shall not exceed 256 MB, and totally no more than } 2 \\
\text { GB for one line. }\end{array}$ \\
\hline
\end{tabular}

The carried-out analysis allowed to select such advantages of the Microsoft Access as: simplicity; flexibility; russification; existence of the various masters, designers; reliability of operation. Among shortcomings users mark: feeble security features and recovery of information; restrictions for information volume; absence of own programming language; low speed by operation with large volumes of information.

Besides, during a study of Microsoft Access DBMS, the following restrictions were found. The database file size (with extension of *.mdb) makes 2 GB minus the place necessary for system objects. The number of storable objects in the database can reach 32768. The number of simultaneously operating users shall not exceed 255; the maximum size of the table - 2 Gbytes; the maximum quantity of fields in table 255; the maximum quantity of indexes in the table - 32; the maximum number of characters in record (apart from system objects) - 2000; the maximum quantity of tables in request 32.

It is expedient to use MS Access for development of simple applications and personal databases with limited scope (several hundreds of thousands of records) of information for the small enterprises [3] which universities do not treat.

\section{$D B M S M y S Q L$}

MySQL is most widespread full-fledged server DBMS. MySQL is the very functional, freely extended DBMS, which is successfully working with different websites and web applications. In spite of the fact that in this DBMS, entire SQL functionality is not realized, MySQL has very many tools for applications programming. In Table II, data types which are supported by MySQL DBMS are presented.
TABLE II. TYPES OF DATA OF MYSQL DBMS

\begin{tabular}{|l|l|}
\hline \multicolumn{1}{|c|}{ Type } & \multicolumn{1}{c|}{ Description } \\
\hline TINYINT & Very small integer values \\
\hline SMALLINT & Small integer values \\
\hline MEDIUMINT & Medium integer values \\
\hline INT, INTEGER & Standard integer values \\
\hline BIGINT & Big integer values \\
\hline FLOAT & Small values with a floating point \\
\hline $\begin{array}{l}\text { DOUBLE, } \\
\text { DOUBLE } \\
\text { PRECISION } \\
\text { REAL }\end{array}$ & Standard values with a floating point \\
\hline $\begin{array}{l}\text { DECIMAL } \\
\text { NUMERIC }\end{array}$ & unpacked value with a floating point \\
\hline DATE & Date \\
\hline DATETIME & Date and time in one value \\
\hline TIMESTAMP & Temporary mark timestamp \\
\hline TIME & Time \\
\hline YEAR & Year \\
\hline CHAR & Line value of the fixed length \\
\hline VARCHAR & Line value of variable length \\
\hline $\begin{array}{l}\text { TINYBLOB } \\
\text { TINYTEXT }\end{array}$ & $\begin{array}{l}\text { BLOB or TEXT value, } 255\left(2^{\wedge} 8-1\right) \text { symbols (the } \\
\text { maximum length) }\end{array}$ \\
\hline $\begin{array}{l}\text { BLOB } \\
\text { TEXT }\end{array}$ & $\begin{array}{l}\text { BLOB or TEXT value, } 65535\left(2^{\wedge} 16-1\right) \text { symbols } \\
\text { the maximum length) }\end{array}$ \\
\hline $\begin{array}{l}\text { MEDIUMBLOB } \\
\text { MEDIUMTEXT }\end{array}$ & $\begin{array}{l}\text { BLOB or TEXT value, } 16777215\left(2^{\wedge} 24-1\right) \\
\text { symbols (the maximum length) }\end{array}$ \\
\hline $\begin{array}{l}\text { LONGBLOB, } \\
\text { LONGTEXT }\end{array}$ & $\begin{array}{l}\text { BLOB or TEXT value, } 4294967296\left(2^{\wedge} 32-1\right) \\
\text { symbols (the maximum length) }\end{array}$ \\
\hline ENUM & List \\
\hline SET & Set \\
\hline
\end{tabular}

The analysis of MySQL has allowed one to mark out such advantages as: simplicity in work (the MySQL installation does not cause difficulties), existence of additional appendices, an opportunity without difficulties to work with a DB. Existence of rich functionality - MySQL supports the majority of functionality of SQL; safety - existence of a large number of the functions ensuring safety which are supported by default. Scalability - MySQL easily works with large volumes of data and is easily scaled. Simplification of some standards allows MySQL to increase information processing speed considerably.

It is necessary to carry to number of shortcomings of MySQL: existence of some restrictions for a functionality in MySQL which is necessary in especially exacting applications; problems with reliability which take place because of some methods of data handling of MySQL (communications, transactions, audits); slow applications programming in MySQL what negative responses of developers of databases testify to.

However, despite existence of the specified shortcomings, there are situations when use of MySQL DBMS is very expedient. This database management system should be used in case of the distributed operations as this system combines an advanced functionality and the free access to the source code. Possessing the high level of safety, MySQL includes easy and at the same time worthy ways of protection of data access.

To make the most efficient use of this system during development of web sites and web applications. The majority of the websites and online applications surely work with MySQL, despite existence of some restrictions. During development of personal decisions, it is also expedient to use 
MySQL as its wide functionality and flexible setup will allow to cope with objectives easily.

The carried-out analysis of two Microsoft Access and MySQL DBMS allowed making a choice in favor of last. The principal argument of this choice was the fact that it is capable to ensure functioning in the multi-user mode provided with existence of the client server mode that is one of decisive factors in case of automation of process of document flow in higher education institution.

In the modern higher education institution, the information flows connected to document flow considerably increased. Data bulks shall be at the same time available to a great number of employees. Therefore, the option with a possibility of multi-user operation in the best way responds research problems. Following advantages of the centralized data storage are obvious:

- data handling becomes simpler and accelerates, their updating on different computers isn't required, these functions are performed by the server and the software;

- instead of a large number of computers of users only one machine (server) needs more reliable information security;

- data handling is shifted from the user personal computers to the server that attracts cut in expenditure on the equipment for users.

Below is a description of the practical part of the study.

In the course of document flow of the modern higher education institution there is a storage and processing of large volumes of information with which operation requires to their constant systematization, extraction, adjustments and deleting. At the same time, data operation is carried not by one structural subdividing. In structure of the Ural Institution of Economics, Management and Low (UIEM\&L), there are following subdividings: library; accounts department; human resources department; dean's offices; selection committee; postgraduate study; computer service; command center quality of education, licensing, accreditation and monitoring.

In case of design of the database, the purpose to automate document flow in all structural subdividings was not set. Within the real research, three structures of higher education institution were considered: selection committee; human resources department; dean's offices. In case of design of the database the special software of MySQL Workbench was used. This tool allows to project diagrams of databases visually. Primary benefits of MySQL Workbench are as follows: product allows one to present database model in the graphic form visually; the product possesses the evident and functional mechanism of installation of cross-table relationships, including "many to many" with creation of the table of communications. Existence of Reverse Engineering allows one to recover structures of tables of already existing $\mathrm{DB}$ on the server, connection needs to be established manually. Presence of the convenient editor of SQL queries, allows one to send at once them to the server and to receive the response in the form of the table; there is a possibility of editing data in the table in the visual mode.

Thanks to a functionality of MySQL Workbench, there was an opportunity to construct evident graphic model of the database. In Fig. 1, the designed model for the Ural Institution of Economics, Management and Low is provided.

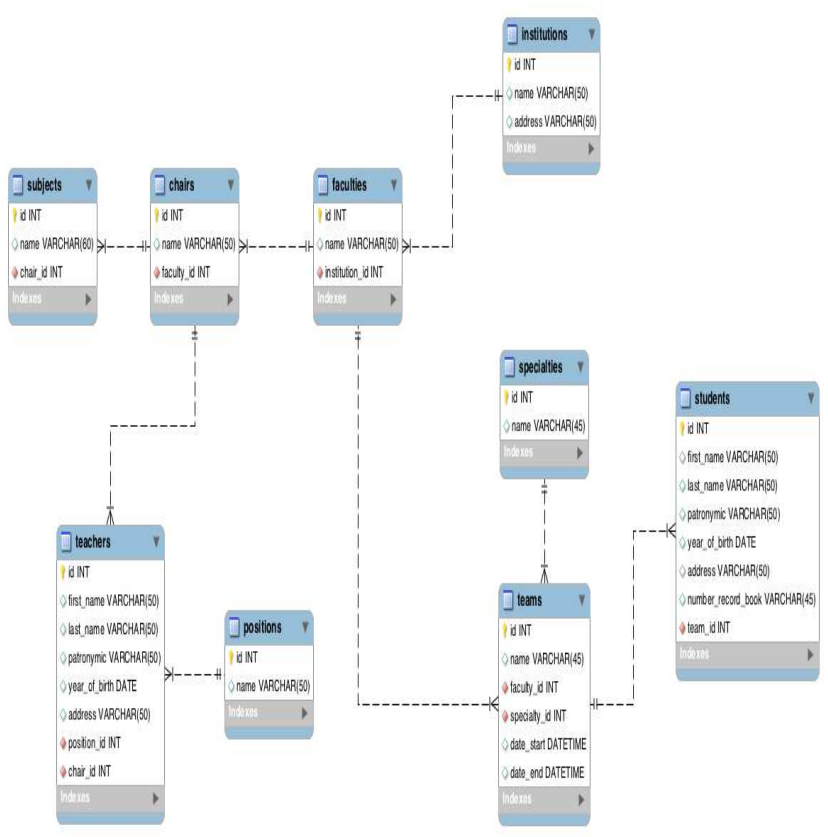

Fig 1. The designed model of the database of the Ural Institution of Economics, Management and Low

As process of automation of three above-named structural subdividings is considered, it is possible to select key tables, to assign each of them primary key and to establish connection in between. We will analyze the designed graphic model consisting of nine tables in which specific data (Table III) are stored.

TABLE III. THE LIST OF THE TABLES WHICH ARE STORED IN THE DATABASE

\begin{tabular}{|l|l|}
\hline \multicolumn{1}{|c|}{ Table } & \multicolumn{1}{c|}{ Table Contents } \\
\hline Institutions & name and address of institute \\
\hline Faculties & list of faculties of institute \\
\hline Chairs & list of departments of institute \\
\hline Subjects & list of disciplines \\
\hline Teachers & list of teachers of institute \\
\hline Positions & list of positions of teachers \\
\hline Specialties & list of the directions of preparation \\
\hline Teams & list of groups of institute \\
\hline Students & list of students of institute \\
\hline
\end{tabular}

In Table IV, the fields which are stored in each of tables are provided.

Let us consider the concepts "primary key" and "foreign key" provided in table 4.

TABLE IV.THE LIST OF TABLES AND FIELDS STORED IN IT

\begin{tabular}{|l|l|}
\hline \multicolumn{1}{|c|}{ Table } & \multicolumn{1}{c|}{ Fields } \\
\hline Institutions & $\begin{array}{l}\text { id - primary key; } \\
\text { name - name of Institution; } \\
\text { address - address of Institution. }\end{array}$ \\
\hline Faculties & $\begin{array}{l}\text { id - primary key; } \\
\text { name - name of Faculty; } \\
\text { Institution_id - foreign key on id Institution. }\end{array}$ \\
\hline Chairs & $\begin{array}{l}\text { id - primary key; } \\
\text { name - name of Chair; } \\
\text { Faculty_id - foreign key on id Faculty. }\end{array}$ \\
\hline Subjects & $\begin{array}{l}\text { id - primary key; } \\
\text { name - name of Subject; } \\
\text { chair_id - foreign key on id chair. }\end{array}$ \\
\hline
\end{tabular}




\begin{tabular}{|c|c|}
\hline Teachers & $\begin{array}{l}\text { id - primary key; } \\
\text { first_name - Teacher first name; } \\
\text { last_name - Teacher last name; } \\
\text { patronymic - Teacher patronimic; } \\
\text { year_of_birth - Teacher year of birth; } \\
\text { address - Teacher address; } \\
\text { position - Teacher position; } \\
\text { chair_id - foreign key on id chair. }\end{array}$ \\
\hline Positions & $\begin{array}{l}\text { id - primary key; } \\
\text { name - position name. }\end{array}$ \\
\hline Specialties & $\begin{array}{l}\text { id - Specialty primary key; } \\
\text { name - Specialty name. }\end{array}$ \\
\hline Teams & $\begin{array}{l}\text { id - Team primary key; } \\
\text { name - Team name; } \\
\text { faculty_id - foreign key on id Faculty; } \\
\text { specialty_id - foreign key on id specialty; } \\
\text { date_start - start date of group training; } \\
\text { date_end - end date of group training. }\end{array}$ \\
\hline Students & $\begin{array}{l}\text { id - primary key of record book; } \\
\text { first_name - student first name; } \\
\text { last_name - student last name; } \\
\text { patronymic - student patronymic; } \\
\text { year_of_birth - Student year of birth; } \\
\text { address - Student address; } \\
\text { group_id - foreign key on id Team. }\end{array}$ \\
\hline
\end{tabular}

Primary key - in a relational data model one of potential keys of the relation selected from quality of the main key (or a key by default) [14]. The foreign key is a column or a combination of columns, which is applied to forced link establishment between data in two tables [5].

Thus, all tables are connected among themselves. At all tables, except for the table students, the id field is created automatically, that is, value one bigger previous is added and never repeats. In the table students number of the record book is taken as a basis of primary key.

One more important feature which can not be ignored is the type of "one-to-many" communication. In case of this type of communication, record from one table communicates with several records of other table, but records from the second table communicate only from one of records of the first table. An example is the tables "teachers" and "positions" [16] figured in fig. 2 .

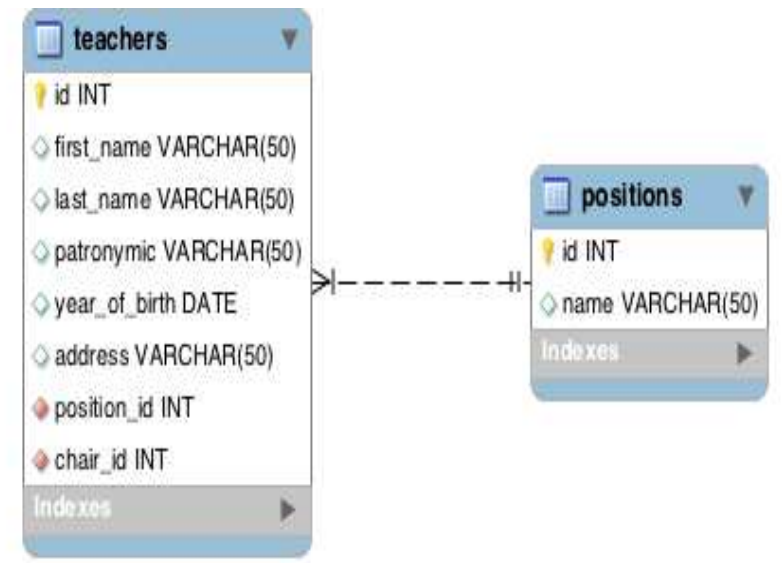

Fig2. "One-to-many" communication on the example of tables "teachers" and "positions"

This type of communication is inherent, for example, in the teacher of institute which has one position (for example, the associate professor), but at the same time the position the associate professor can concern to many teachers. It should be noted that all tables of the designed model provided in fig. 1 are connected among themselves by communication type "one-to-many".

When the graphic model of the database of three structural subdividings is constructed, it needs to be placed on the server that will allow to realize SQL queries to the database and to develop the special interface for filling, deleting, change of data, and also obtaining reports by different criteria. For placement of the database on the server, it is not necessary to create tables by means of specialized requests, it will make MySQL Workbench. It will establish connection with the server and the database structure by means of a special script "is mirrored" on the server. The following step it is necessary to make SQL requests for data management and to develop the interface for automation of different sections of operation in structural subdividings that will allow storing data it is ordered, and also will spare resources in the considered areas.

Resources are supposed to be the main and principal resource in the modern society - a temporal resource. Automation of different areas implies an acceleration of worker processes, and also reliability of data storage. The issue of reliability of data storage is resolved as they are stored on the server possessing high technical characteristics, and working in case of uninterrupted power.

Acceleration of data processing is reached, on the one hand, thanks to the fact that it is carried out on the server. On the other hand, the comfortable, evident and "friendly" interface of the user can accelerate processing of data. If correctly designed interface is not developed, the user will not be able quickly to work with the database as on each database request it should create specialized SQL queries for receiving, editing, deleting data.

SQL - "structured query language" - the formal nonprocedural programming language applied to creation, modification and data management in arbitrary relational database, by the controlled appropriate database management system (DMBS) [7].

Within the research, the specialized interface was created. Further, its operation directly on SQL-database requests will be considered. In the database, there are nine tables which detailed description is given above. The main table is the table of institutions, which stores in itself the name and the address of institute. How it is provided in the specialized interface is shown in fig. 3 . 


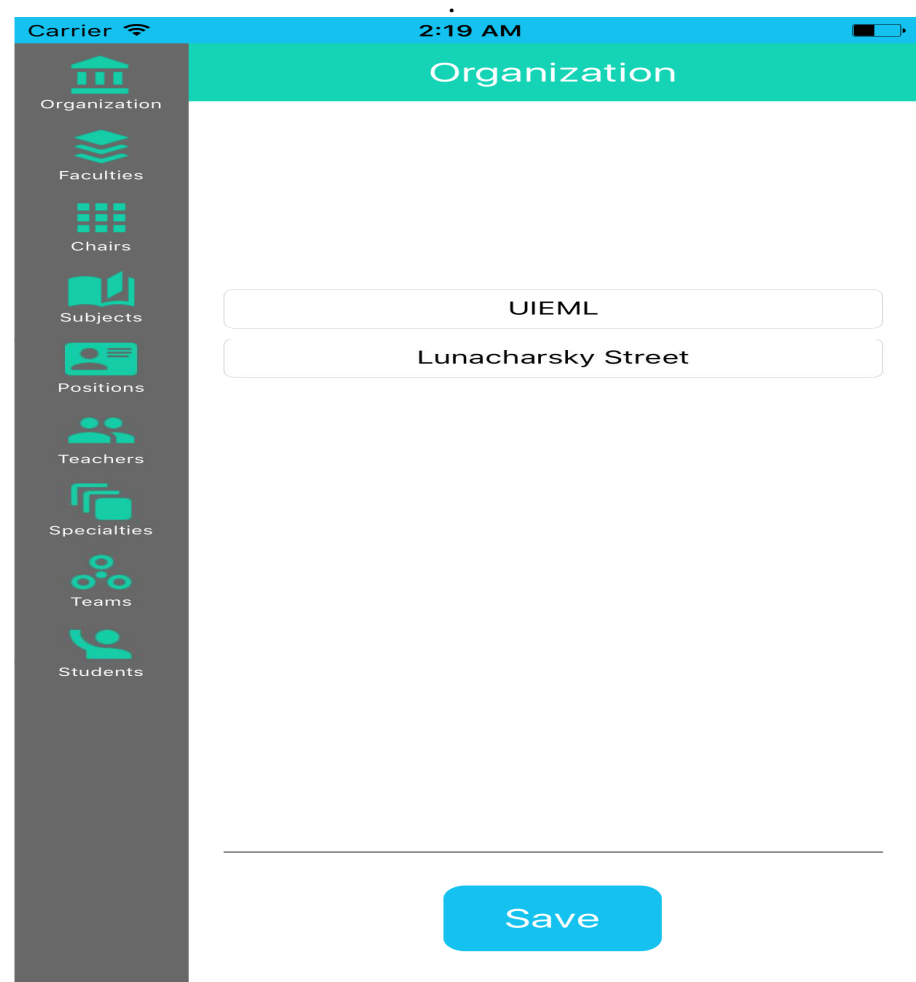

Fig 3. The interface for filling of information about institute

In fig. 3, there are two special fields. One field contains the name of institute, another - the address. The third element is the Save button on clicking which the special database request will be solved. The request is filled with data from the designated fields; further data are registered in the database. The database request looks as follows:

INSERT IGNORE INTO institutions VALUES (NULL, 'UIEM\&L', 'Lunacharsky 194')

The INSERT command is responsible for entering of data into the database. Thus, in the table institutions data from the UIEM\&L fields and "Lunacharsky 194" remain. After data on the organization are entered in the database, it is possible to enter remaining data in the tables which are specially intended for this purpose.

In the structure of each institute, there are faculties for which the special table faculties is created. To view data on faculties, it is necessary to create a request for data sampling from the appropriate table. This request looks as follows:

SELECT faculties.id, faculties.name, institutions.name

FROM faculties, institutions

WHERE institutions.id = institution_id

For data sampling the SELECT command is used, further it is specified what fields it is necessary to remove, namely, primary key of faculty of "faculties.id", the name of faculty "faculties.name", the name of institutions.name institute. After fields for data output are listed, tables from which data sampling, by means of the FROM command will be carried out are specified. In this command, it is necessary to list the tables "faculties" and "institutions" from which data will be displayed. The final stage in this request is establishment compliance of primary and foreign keys. It is provided thanks to "one-to-many" link establishment between the table institutions and the table faculties. Thus, primary and foreign keys will correspond each other. In other words, the faculty will correspond to institute.

Every time to enter this request very difficult therefore appearance of the interface for this request is provided in fig. 4.

In fig. 4 there is an icon "+", clicking which carries to adding on the screen of additional faculty. We will consider this screen in fig. 5 .

In fig. 5, in addition to a field for filling of the name of faculty, there are two buttons "Save" and "Delete", clicking which will execute a special database request. The Save button will execute an append query of new entry in the database which looks as follows:

INSERT IGNORE INTO faculties (name, institution_id)

SELECT 'Faculty of Economy', institutions.id

FROM institutions WHERE name='uiem\&l'

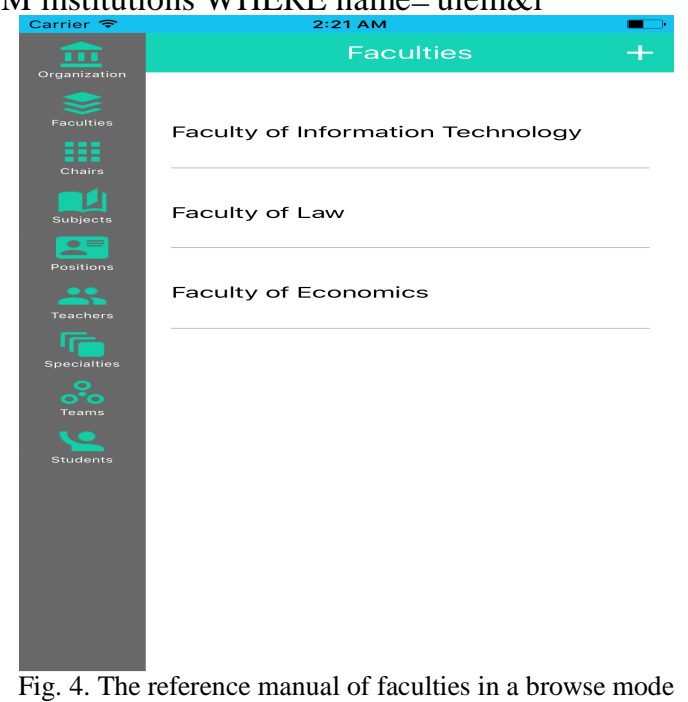

This request will add data to the table faculties by means of the INSERT command (in parentheses fields to which it is necessary to add data are listed (name, institutions)). To add data in the field of name, just it is necessary to specify the name of faculty "Faculty of IT". Further, it is necessary to specify foreign key of "institutions.id". For this purpose, it is necessary to make a subquery to the database to receive primary key of institute where the name of UIEM\&L institute is stored. In order that the request fulfilled truly, it is necessary to specify the table of institutions institutes in which the primary key is stored. Specifying of the table happens to the help of the FROM command. 


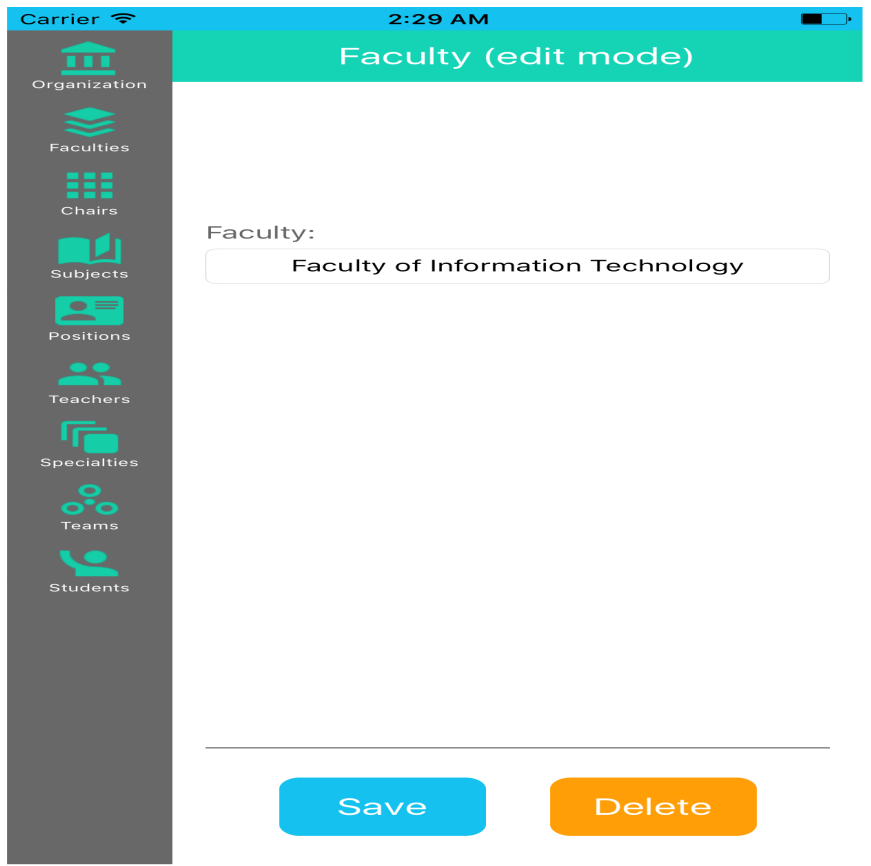

Fig. 5. Adding of additional faculty

Data on faculties it is possible as well to delete from the database. It becomes by means of clicking the Delete button (fig. 5). At the time of clicking, there is a database request:

DELETE FROM faculties WHERE name='faculty of IT'

The DELETE command is responsible for deleting data. Further, by analogy, it is necessary to specify from what table it is necessary to delete data; in this case, it is the table faculties. But not to delete all data, it is necessary to set a condition by means of the WHERE command. In this example, a condition is "the faculty of IT". Thanks to this request, "the faculty of IT" will be removed from the table "faculties".

We reviewed database requests for operation with the table faculties. According to fig. 1 still the most part of tables to which it is necessary to make requests isn't considered. All requests on structure are similar to the example of requests given above to the table faculties. The limited scope of article doesn't allow to review requests to remaining tables and the interface developed for them. Within the research menu items of "Department", "Objects", "Positions", "Specialties", "Groups" were considered.

Development assessment. The created database which is information basis of the developed service of automation of process of compilation of the schedule in higher education institution as mobile application allows to review append queries, deleting and data sampling. So, to add data on objects and departments structural subdividing "Dean's offices" can add data on positions and teachers - structural subdividing "Human resources department", to add data on students, groups and specialties - structural subdividing "Selection committee". The structure and the interface of the created database allows parallelizing the operation connected to document flow between structural subdividings. At the same time, reliability of data as they are concentrated on the server that promotes an acceleration of process of document flow of subdividings is provided and increases quality of their operation.

Main outputs. Technological development process of service of automation of document flow in higher education institution as mobile application, being an informatization process step, allowing to improve controllability corporate data and processes in operating conditions of the Unified Information System (UIS) of institute is described. Existence of complete UIS of higher education institution will give the chance to control knowledge that will allow to develop innovations, to improve a staff susceptibility (to quicker solve originating problems), to increase labor productivity (to reduce search time of the necessary decision in control and amount of completed work in educational process), to develop competence of a staff.

Document management in higher education institutions on the basis of the proposed solution requires transition to such status of UIS of higher education institution upon which users get access to necessary, up-to-date, complete, incorrect and consistent information. And IT solutions are so interwoven into the main business processes of higher education institution that a staff and students will not be able to do without services provided by the information environment any more. At the same time, functions are executed by a staff with bigger efficiency, and quality of training of students increases that makes investments into IT economically justified.

Implementation of the offered approach is directed to enhancement of educational management on the basis of the information and education environment of higher education institution which is understood as set of purposefully created conditions of interaction of all categories of users. And there are UIS interactive program resources (educational, administrative, information, educational) on the basis of network technologies, program and technical means providing uniform technological means of information support of students, teachers, parents, administration of educational institutions and the public.

\section{Acknowledgements}

The authors of this article want to express gratitude to administration of a construction institution of Ural federal university named after the First President of Russia B. N. Yeltsin for the financial support given in connection with the article publication.

\section{References}

[1] Databases - Lesson 1. Concept of the database, online, available at <http: www.site-do.ru="" db="" db1.php="">.

[2] Data types in Access 2010, online, available at <http: www.programmschool.ru=""data_type_access2010.html="">.

[3] Main opportunities and restrictions of DBMS Access, online, available at <http: lektsii.net="" 1-105897.html="">.

[4] Primary key, online, available at <https: ru.wikipedia.org="" wiki="" pervichnyy_klyuch="">.

[5] Restrictions of FOREIGN KEY, online, available at <https: technet.microsoft.com="" ru-ru="" library="'" ms175464(v="sql.105)" .aspx="">.

[6] Entering of data into the table, online, available at <https://support.office.com/ru-ru/article/ rukovodstvo-po-svjazjammezdu-tablicami-8a027791-b8a3-4a32-a99e06c4e272c45>. 
[7] SQL, online, available at 〈https: ru.wikipedia.org="" wiki="" sql="">.

[8] A.N. Asaul, B.M. Kaparov, "Control of a higher educational institution in the conditions of innovative economy", SPb., Gumanistika, 2007.

[9] V. Zernov, "The higher education as a resource of innovative development of Russia", "The Higher education in Russia", vol. 1, pp. 12-22, 2008.

[10] L.N. Kachalina, "Competitive management", M., Eksmo, 2006.

[11] V.V. Hooks, K.I. Shakhgeldyan, "Corporate information environment of higher education institution", Vladivostok, Dalnauka, 2007.

[12] V.V. Levshina, E.S. Bouck, "Formation of a quality management system of higher education institution" monograph, SIBGTU, Krasnoyarsk, 2004.

[13] N.L. Ponomarev, B.M. Smirnov, "Educational innovations. State policy and control", M., "Academy", 2007.

[14] I.V. Robert, "Theory and technique of informatization of education (psychology and pedagogical and technological aspects)", M., Institute of education informatization of Russian joint stock company, 2008

[15] N.A. Seleznyova, "Quality of the higher education as object of a system research: lecture report", Research center of problems of quality of training of experts, 6th prod., stereotype, M, 2006.

[16] E. Stepkina, "What is "business activity" of higher education institution?", 'The higher education in Russia", 2007, vol. 2, pp. 30-36.

[17] V. Titov, M. Endovitsky, "The directions of interaction of higher education institutions and business community", "The Higher education in Russia”, vol. 7, pp. 10-18, 2007. 